\title{
Massagem Tui Na e desenvolvimento escolar: percepção dos cuidadores
}

\author{
Juliane Pagliari Araujo1, Luciana Cláudia Rizzo Lima², Juliana Gomes Fernandes³, \\ Simone Roecker ${ }^{4}$, Jackeline Tiemy Guinosa Siraichi ${ }^{5}$
}

\begin{abstract}
RESUMO
Transtorno e Déficit de Atenção e Hiperatividade (TDAH) é um distúrbio que afeta a atenção e o controle dos impulsos nas crianças/ adolescentes, prejudicando a realização das atividades escolares e diárias. Objetivou-se conhecer a percepção dos cuidadores sobre os efeitos da massagem Tui Na na vida escolar das crianças/adolescentes. Foram realizadas entrevistas semiestruturadas com cuidadores de crianças/adolescentes que estudavam no ensino fundamental e que participaram de sessões de massagem Tui Na. As entrevistas foram realizadas entre setembro e novembro de 2013 e submetidas a análise de conteúdo. Os cuidadores perceberam que as crianças/adolescentes com TDAH sofriam discriminação no ambiente escolar e que os educadores, em sua maioria, não estavam preparados e não eram tolerantes para lidar com essas crianças/adolescentes. Após a realização da massagem as crianças/adolescentes demonstraram maior receptividade com as atividades escolares, bem como, melhoraram o nível de concentração, de atenção, de alegria e bem-estar.
\end{abstract}

Descritores: Transtorno do Déficit de Atenção com Hiperatividade; Educação; Massagem

\section{Tui Na massage and development school: perception of caregivers}

\begin{abstract}
Attention Deficit Hyperactivity Disorder (ADHD) is a disorder that affects attention and impulse control in children/adolescents, undermining the school and daily activities. The aim of this study was to know the perception of caregivers about school life of children/ adolescents after sessions of Tui Na massage. Semi-structured interviews were conducted with their caregivers after attended sessions of Tui Na massage. The interviews were conducted between September and November, 2013, and submitted to content analysis. Caregivers realized that children/ adolescents with ADHD suffered discrimination at school and educators, in most cases, were not prepared and were not tolerant to handle these children/adolescents. After completing the massage sessions, children/adolescents showed greater responsiveness with school activities, as well as improved their level of concentration, attention, happiness, and well-being.
\end{abstract}

Descriptors: Attention Deficit Hyperactivity Disorder; Education; Massage.

\footnotetext{
${ }^{1}$ Mestre em Biociências e Saúde pela Universidade Estadual do Oeste do Paraná (UNIOESTE), Cascavel, PR, Brasil.

${ }^{2}$ Técnica em Enfermagem pelo Instituto Federal do Paraná (IFPR), Londrina, PR, Brasil.

${ }^{3}$ Fisioterapia pela Universidade Estadual de Londrina (UEL), Londrina, PR, Brasil.

${ }^{4}$ Mestre em Enfermagem pela Universidade Estadual de Maringá (UEM), Maringá, PR, Brasil.

${ }^{5}$ Doutora em Ciências Farmacêuticas pela Universidade Estadual de Maringá (UEM), Maringá, PR, Brasil.
} 


\section{Introdução}

O Transtorno e Déficit de Atenção e Hiperatividade (TDAH) é uma patologia caracterizada por desatenção, hiperatividade e impulsividade, com maior prevalência na infância ${ }^{1}$. É considerado um transtorno crônico relacionado ao desenvolvimento humano, com comprometimento significativo nos comportamentos social, emocional e educacional das crianças e dos adolescentes ${ }^{2-3}$. Portanto, envolve inúmeras dúvidas, seja dos pais, professores e todos os envolvidos na vida do portador desta patologia. A falta de conhecimento e apoio especializado contribui para que esta criança/ adolescente seja definida como indisciplinada e em alguns casos, pouco inteligente 4 .

Muitas vezes os sinais são imperceptíveis aos olhos dos pais, ou simplesmente, não querem ver o comportamento inadequado e inconveniente do filho, e que na maioria das vezes são percebidos somente na escola, por professores e educadores. Visto a dificuldade dos pais em realizar uma análise do comportamento do próprio filho, torna-se fundamental que a equipe multiprofissional, que não apresenta envolvimento afetivo, exponha aos pais a realidade vivida pela criança/ adolescente. $O$ esclarecimento sobre os sinais clássicos do transtorno e a orientação para que busquem de ajuda especializada são fundamentais para que o problema não se agrave com o passar do tempo ${ }^{5}$.

O TDAH manifesta-se geralmente, antes dos sete anos de idade, podendo persistir até a vida adulta. Porém, a criança portadora desse transtorno geralmente começa a ser diferenciada das outras no início do ensino fundamental, já que nesta fase, os problemas começam a despontar, devido a maior exigência da atenção, $0^{3,6,7}$.

A criança/adolescente portadora de TDAH comete erros por falta de atenção, tem dificuldade em manter a concentração, parece não ouvir quando chamado, não é capaz de seguir instruções ou concluir atividades, tem dificuldade para organizar-se ao realizar tarefas escolares ou atividades domésticas, não gosta de fazer atividades que necessitem de muita atenção, perde objetos com frequência e se distrai com facilidade ${ }^{8}$.

Neste sentido, é importante que os professores tenham algum conhecimento sobre o TDAH, para que não haja barreira junto ao aluno, mas sim, uma interação entre ambos, havendo um equilíbrio entre a atenção dada aos demais, porém, com maior atenção a esse aluno em particular. Ações como sentar próximo à professora, turmas menores, sala sem muitos detalhes, para que não disperse a atenção do aluno e atividades mais curtas, ou ainda, com permissão para que possa ser feita em maior tempo, são algumas das sugestões para os profissionais da escola ${ }^{9}$.

As terapias complementares têm sido utilizadas para auxiliar no tratamento do TDAH, diminuindo sintomas de agitação, falta de atenção e apresentam também maior interação no convívio com os pais e irmãos. Dentre elas, tem-se que a massagem Tui $\mathrm{Na}$ aponta resultados satisfatórios para esse fim $^{10}$. Estudo mostrou que após sessões de massagem, adolescentes com TDAH ficaram mais alegres e menos inquietos, e após duas semanas, estavam permanecendo mais tempo em sala de aula e menos hiperativos do que anteriormente ${ }^{11}$.

Diante do exposto, a integração dos pais e dos profissionais da educação faz-se necessária para que as crianças/ adolescentes sejam vistas em sua totalidade. Assim, o objetivo deste estudo foi conhecer a percepção dos cuidadores sobre os efeitos da massagem Tui Na na vida escolar das crianças/adolescentes.

\section{Metodologia}

Trata-se de um estudo descritivo-exploratório, com abordagem qualitativa, realizado no município de Londrina - PR. Participaram do estudo nove cuidadores legais de crianças/adolescentes matriculadas entre o quinto e o oitavo ano de uma escola estadual localizada na área central do município.

As crianças/adolescentes foram selecionadas pela equipe pedagógica da referida escola para participarem do Projeto "Intervenção da massagem Tui Na na criança e adolescente com Transtorno e Déficit de Atenção e Hiperatividade" desenvolvido em parceria entre os cursos técnicos em massoterapia e enfermagem do Instituto Federal do Paraná - Campus Londrina.

Como critérios de inclusão para o referido projeto, foram definidos que a criança/adolescente deveria ter um laudo médico com o diagnóstico de TDAH e os cuidadores autorizassem a participação no projeto. Foram realizadas reuniões com os cuidadores e as crianças/adolescentes orientando-os sobre a metodologia, bem como, demonstrando como seria realizada a massagem Tui $\mathrm{Na}$. Todas as etapas do projeto foram realizadas na escola onde as crianças/adolescentes estudavam para valorização do espaço e confiabilidade por um ambiente já conhecido. 
Após o término das intervenções de massagem Tui $\mathrm{Na}$, realizou-se a coleta de dados que ocorreu entre os meses de setembro e novembro de 2013. A técnica utilizada para coleta do material empírico foi a entrevista semiestruturada, das quais participaram os cuidadores das crianças/adolescente que haviam participado das massagens, que totalizaram doze sessões.

As entrevistas foram agendadas previamente via telefone e na data e horário marcados o pesquisador dirigiu-se até 0 local indicado pelos participantes, sendo em todos os casos, o domicílio. Antes da entrevista, o pesquisador explanou aos participantes todas as informações pertinentes ao estudo e os mesmos subscreveram os Termos de Consentimento Livre e Esclarecido em duas vias. Os dados foram gravados em gravador tipo digital, transcritos e posteriormente destruídos. Para a realização das entrevistas foi utilizado um roteiro norteador, constituído de duas partes: a primeira, com questões objetivas concernentes ao perfil sociodemográfico e a segunda, com questões abertas relacionadas às percepções dos cuidadores sobre os efeitos da massagem Tui Na nas crianças/adolescentes no ambiente escolar.

Os dados foram submetidos à análise de conteúdo. Realizou-se a leitura exaustiva, codificação, enumeração, classificação e agregação do materia| ${ }^{12}$. Feita a identificação das unidades de interesse, dos aspectos comuns entre elas, e das inferências, procedeu-se à interpretação e categorização dos dados obtidos, os quais foram contrastados com a literatura científica sobre a temática. Para diferenciar e preservar a identidade dos cuidadores, foi utilizado como código a letra 'C' seguida de numeral arábico, de acordo com a ordem de realização das entrevistas (C1 a C9).

Para a execução desta pesquisa foram observados os aspectos éticos propostos pelas Diretrizes e Normas de Pesquisa em Seres Humanos, por meio da Resolução 466/12 do Conselho Nacional de Saúde ${ }^{13}$ e aprovação do projeto pelo Comitê de Ética em Pesquisas da Universidade Federal do Paraná (CAAE: 13924113.7.0000.0102, Parecer 391.470/2013).

\section{Resultados e discussão}

\section{Conhecendo os cuidadores e suas famílias}

A presente pesquisa foi realizada com os cuidadores de crianças/adolescentes com diagnóstico de TDAH que participaram das 12 sessões de massagem Tui Na. Onze crianças e adolescentes participaram do projeto, no entanto, nove entrevistas foram realizadas, sendo que duas mães tinham mais que um filho inscrito no projeto. Dos participantes desta pesquisa, oito eram mães e apenas uma era avó da criança, sendo incluída por caracterizar-se como cuidadora legal.

A idade das mães variou entre 33 e 48 anos, e a avó tinha 67 anos. Das nove entrevistadas, seis eram casadas, duas solteiras e uma viúva. Todas moravam em casas de alvenaria, com energia elétrica e água encanada, apenas uma entrevistada relatou que na sua casa o sistema de despejo dos dejetos era por meio de fossa, pois ainda não estava disponível a rede pública de esgoto na região onde reside.

Com relação ao número de filhos a variação é de dois a três filhos por família, sendo que, duas famílias possuem mais de um filho com diagnóstico de TDAH.

Em relação ao tempo de diagnóstico verificou-se que uma criança/adolescente foi diagnosticada com três anos de idade, cinco foram diagnosticadas entre cinco e sete anos e outras cinco crianças/adolescentes entre oito e doze anos. Ressalta-se que todas as crianças/adolescentes fazem uso de medicamento alopático.

As famílias cujos filhos são um casal, ou mais, estes dormem cada um em seu quarto, separando as meninas dos meninos. Todas as casas tem sala e cozinha separada, um banheiro e uma área de serviço. Uma casa possui um cômodo alocado para escritório, e em outra tem poço de claridade.

Verificou-se que a renda familiar variava entre mil e quatrocentos reais a três mil reais. Em todas as famílias as mães participavam da renda familiar trabalhando formalmente, com registro em carteira, ou com renda informal, a avó era aposentada. Quanto à religião, cinco entrevistadas declararam-se católicas e quatro evangélicas. Com relação à escolaridade, quatro mães completaram o ensino médio, quatro possuem somente o ensino fundamental, e a avó é alfabetizada.

Do processo de análise de conteúdo dos discursos emanaram duas categorias, que delinearam a percepção dos cuidadores em relação ao TDAH e desenvolvimento escolar das crianças/adolescentes: TDAH e escola: percepção dos cuidadores; TDAH, escola e massagem Tui Na: nova percepção dos cuidadores. 


\section{TDAH e escola: percepção dos cuidadores}

Os sintomas do TDAH são observados desde muito cedo na infância, entretanto, é no ambiente escolar que são percebidos com maior magnitude. As dificuldades de atenção e de hiperatividade destas crianças são reconhecidas por professores quando comparadas a outras crianças da mesma idade, e é neste contexto escolar que a impulsividade e a inquietude da criança, são muitas vezes, interpretadas como indisciplina, e a desatenção como negligência ${ }^{14}$.

As crianças/adolescentes que participaram do projeto permaneciam no ambiente escolar durante, aproximadamente, cinco horas por dia e uma das dificuldades enfrentadas pelas mães, refere-se a este ambiente, pois, encontrar uma escola preparada, que aceite seu filho, ajudando-o nas suas limitações e dificuldades, não é tarefa fácil.

[...] aquela professora dele do pré me disse que ele era normal, que até final do ano ele ia aprender, acho que ela não queria ver o problema, era melhor para ela assim, só no terceiro ano quando ele mudou de escola, que a professora viu que ele não estava nem alfabetizado ainda, ele teve que voltar e fazer o primeiro ano de novo junto com o terceiro, um reforço, sabe, aí que eu fui atrás de médico, marquei, e ele disse o que era (C8).

Afirma-se que, os profissionais de várias áreas, inclusive da educação, têm demonstrado crescente preocupação sobre o TDAH no intuito de obter mais entendimento. Assim essa compreensão é de extrema importância, uma vez que estas crianças podem vir a receber rótulos de indisciplinados pelos familiares e educadores, sendo que diagnosticar 0 TDAH não é tarefa do professor, porém, suas observações sobre este aluno podem ajudar na sua identificação ${ }^{15}$.

A falta de conhecimento por profissionais da área da saúde e educação é percebida em uma das entrevistas, no qual o cuidador relata a dificuldade encontrada em ter o diagnóstico para o seu filho logo no início da vida escolar da criança.

[...] quando ele estava na outra escola, na escola municipal, ele estava acho que no segundo aninho, desde ali eles já reclamavam do comportamento dele, que ele não deixava ninguém quieto, ele mexia com todo mundo, ele ficava sentado na cadeira, mas ele não ficava quieto, ele estava batendo o lápis, batendo com as mãos, dedilhando na carteira com as mãos, fazendo barulho com a boca, passando a mão na parede, sempre procurando fazer algum barulho. Direto eles chamavam a gente para ir lá conversar sobre isso, sobre o comportamento dele, eu pedi que a escola fizesse uma avaliação, eles falaram para mim que fizeram e não deu nada, que ele era normal, que não tinha hiperatividade[...] (C9).

O portador de TDAH necessita de um esforço conjunto de várias pessoas, incluindo pais, educadores, equipe multiprofissional e a própria criança que atuem em algum tipo de intervenção, como orientação aos pais e professores, psicoterapia e acompanhamento medicamentoso, visando a qualidade de vida desta criança/adolescente ${ }^{15}$.

Nesta situação o apoio da família e da escola é fundamental e determinante no desenvolvimento da criança/adolescente com TDAH. Assim, a escola exerce um papel indispensável na detecção, compreensão e acompanhamento da criançal adolescente, pois é neste ambiente que elas passam grande parte de suas vidas.

Comumente não são os pais que identificam o transtorno, esta observação vêm de pessoas que convivem com outras crianças/adolescentes e conseguem comparar o seu comportamento, e vêem a diferença entre elas. Desta forma, percebe-se a importância de tal cuidado e observação no ambiente escolar, pois muitas vezes a indicação de que esta criança precisa ser acompanhada por profissionais é realizada pela equipe escolar.

Quando a professora do terceiro ano me falou da dificuldade dele de aprendizado eu fui marcar consulta para ele, foi difícil, demorado, mais ele faz acompanhamento médico [...] (C8).

Os professores não têm plenas condições de identificar se as crianças que possuem algumas características de TDAH são portadoras deste transtorno, porém eles podem orientar a família a observar a criança, e se necessário, providenciar a atenção de profissionais qualificados ${ }^{16}$.Os profissionais da educação precisam ter formação adequada para trabalharem com crianças/ adolescentes portadores de TDAH e, além disso, também existe a necessidade do comprometimento do professor, da procura pela formação continuada e da dedicação ao ensino para apoiar as crianças/adolescentes e seus cuidadores². 
As dificuldades enfrentadas pelas crianças com TDAH, tanto no âmbito escolar, quanto familiar, provocam prejuízos sociais, emocionais e acadêmicos. A maioria das crianças com hiperatividade ao ingressarem na escola, tornam-se candidatas a repetências sucessivas desde o início do ensino fundamental, pois a criança é obrigada a se adaptar a um grupo maior, a cooperar com os colegas em atividades estruturadas e a ficar longo tempo sentado. Essas atividades podem ter exigências dificeis para crianças sem o transtorno, para crianças hiperativas tornam-se uma tortura ${ }^{17}$.

Quanto mais cedo estas crianças tiverem o diagnóstico e iniciarem o tratamento adequado, e o uso de terapias complementares, melhor será a qualidade de vida, desempenho escolar, relacionamento familiar e social. Estas crianças sofrem muito quando chegam à idade escolar, com muitas dificuldades de acompanhar os colegas, tendo notas mais baixas e um índice grande de repetência.

[...] ele tem dificuldade em leitura e escrita errada [...] este final de ano ele ficou em recuperação e precisava de bastante nota, bastante mesmo [...]Mas eu tenho uma pessoa aqui perto da minha casa que dá aula para ele, que dá uma atenção, e ele é excelente pessoa [...] esse rapaz ajudou ele a alfabetizar [...]eu vi que ele ainda precisa de ajuda [...] (C2).

Na verdade ele repetiu, o ano passado ele repetiu, tanto que esse doutor $A$. falou que se ele já tivesse tomado Ritalina® isso não teria acontecido [...] (C9).

Essas crianças passam por sucessivas transferências, devido à falta de recursos pedagógicos das escolas, outra constante, são as solicitações de comparecimento dos pais à escola, ocasiões nas quais houveram queixas a respeito do comportamento e do desempenho de seus filhos.

No depoimento a seguir fica evidente o preconceito que sofre uma criança/adolescente com TDAH, e o sofrimento pelo qual passam os pais com os comentários das demais crianças e, especialmente, dos professores e funcionários da instituição de ensino. Fatos estes que elevam as chances de agravamento dos problemas já enfrentados pela criança e seus familiares.

E ele está pelo terceiro ano na sexta série [...] No colégio, já tive várias vezes que tirar ele de lá, até o diretor já me convidou a tirar ele de lá, porque desde quando ele entrou lá, desde o primeiro ano, ele sempre foi massacrado, assim, pela atitude dele, pelo jeito dele, nossa já escutei horrores ali dentro [...] era só crítica, e ele também sofria muito, porque ele era muito mais gordo, com a molecada chamando ele de bujão, baleia, e isso a gente não podia contar com ninguém, que se vai falar com o professor, passa batido, se vai falar com o diretor, mesma coisa que nada [...] no primeiro ano dele que a M.[diretora] chamou eu para ir conversar lá com ela, e falou horrores para mim, que aquele dia eu cheguei em casa, nossa eu não queria nem fazer nada, deitei na cama, só chorava, ela falava que: ali ninguém gostava dele, que não sei o que meu menino estava fazendo naquele colégio porque eu não tirava ele de lá, porque ninguém gostava dele ali, primeiro dia de aula do menino naquela escola [choro] [...] (C7).

Estudo realizado com mães de crianças com o transtorno ressalta a tristeza que estas mães sentem com a discriminação que seus filhos sofrem, percebendo inclusive que seus filhos ficam chateados com o tratamento recebido dos colegas e de parentes, às vezes até mesmo do pai ${ }^{18}$.

Assim em muitos casos as crianças/adolescentes com TDAH sofrem bullyng, que possui como consequências danos e traumas irreparáveis, podendo refletir em baixa autoestima, irritabilidade, estresse, depressão, queda no rendimento escolar, dificuldades de relacionamento, pensamentos de vingança para com o agressor e até mesmo suicídio (LEÃO, 2010) ${ }^{19}$.

Quanto ao relato dos cuidadores sobre esta dificuldade no ambiente escolar, ao qual descrevem como falta de aceitação, percebe-se a dificuldade dos educadores, visto que o número de alunos com as características de TDAH matriculados nas escolas é cada vez maior.

A turma deixou de ser homogênea, onde todos aprendem juntos e passou a ter características bem distintas, tornando o trabalho do educador cada vez mais desafiador com novos padrões de comportamento de crianças e com necessidades especiais que agora começam a fazer parte do novo quadro de alunos matriculados na escola. Conviver com essa diversidade pode causar nos educadores uma certa inquietação é um desafio ${ }^{20}$.

A dificuldade que os pais de crianças portadoras de TDAH apresentam, são muitas vezes expressadas pela dor que sentem ao ver o que seus filhos passam e sabem que vão passar. Por muitas vezes a busca de ajuda, apoio, explicações, nem sempre é bem sucedida, sendo que, quando a família encontra alguém que olhe para seu filho, com intuito de ajudar, a satisfação é premente. 
[...] tem gente que fala: nossa! Você aqui de novo! O que que foi dessa vez? Então a gente que tem o filho dessa forma, embora todo mundo quer excluir, ele precisa de ajuda! Então, o hiperativo precisa de ajuda! A família precisa de ajuda, e não é botando ele para correr, não é criticando, que vai resolver o problema, hiperativo tem muito por aí, são pessoas que depois de adulto, tem uma vida profissional melhor que muitos que se dizem os bons dentro da escola, você vê lá na escola menino que deu muito trabalho hoje são os melhores na sala de aula [...] (C7).

A participação de toda equipe pedagógica e multidisciplinar no acompanhamento da criança/adolescente com TDAH faz toda a diferença no cotidiano escolar. Ao professor, fica evidente a importância da solicitação de ajuda, quando achar necessário, do educador ao psicopedagogo, ou psicólogo infantil, visto que esses profissionais têm um melhor entendimento sobre TDAH e conhecem os recursos necessários para uma sala de aula, podendo ofecer o suporte necessário para lidar com a criança/adolescente hiperativa ${ }^{15}$.

Os cuidadores buscam compreensão e auxílio em relação as dificuldades enfrentadas da demanda de uma criança com TDAH, tanto no ambiente familiar, quanto no escolar, esperando que seu filho seja aceito e integrado na sociedade em que vive, e que estes ambientes estejam preparados para recebê-lo, aceitá-lo e ajudá-lo com suas limitações.

\section{TDAH, escola e massagem Tui Na: nova percepcão dos cuidadores}

É crescente o interesse pela prática da terapia complementar que faz uso de técnicas que visam à assistência à saúde do indivíduo, considerando-o de forma holística, como mente/corpo e espírito e não como um encaixe de partes isoladas.

A terapia complementar é indicada devido a crença sobre a sua eficácia seguida da experiência pessoal ${ }^{21}$, porém é conhecido que técnicas complementares que fazem o uso do toque, como a massagem, apresentam resultados científicos comprovados em relação a sua eficácia, como efeitos fisiológicos que levam ao aumento do aporte circulatório, incremento da imunidade, e alterações hormonais que acarretam no relaxamento e sensação de bem-estar ${ }^{22-24}$.

Estes benefícios da massagem vêm ao encontro com as expectativas dos cuidadores em ter algo que auxilie seus filhos com TDAH a superar as dificuldades vividas no cotidiano, proporcionando a criança/adolescente um relaxamento, trazendo maior controle sobre a agitação, podendo tornar-se uma forma de tratamento complementar.

Foi ótima, retorno muito positivo [...] com a massagem ele ficou mais tranquilo, a gente percebeu que a coordenação dele melhorou, mesmo a gente fazendo alguns auxilios de exercícios e ele está sem medicamento há três meses. Então, a gente está vendo melhoras nele constante, ele está bem mais calmo, [...] eu fiquei muito feliz porque todos os projetos que tenha assim dentro de algo que é gratuito, eu sempre me cadastro [...] (C1).

Eu achei uma maravilha, na realidade nunca imaginei que uma escola pública pudesse ter um projeto como esse, na realidade eu acompanhava ele durante a massagem [...], e é ótimo sim, sem dúvida nenhuma [...] (C6).

Por conviver com os comportamentos do TDAH e reconhecer o sofrimento, tanto para o filho como para elas, as mães passam a buscar alternativas para ajudar o filho ${ }^{18}$. Desta forma, projetos e terapias direcionados às crianças/ adolescentes com transtorno podem auxiliar na melhora contínua dos sintomas característicos do TDAH, visto que a aceitação por ambas as partes foi satisfatória.

Estudo ressalta que além da aceitação é fundamental a participação dos pais e/ou encarregados da educação, no apoio ao tratamento, modificando hábitos diários da criança (alimentação, descanso e atividade) e também cooperando ativamente com o tratamento, quando necessário ${ }^{25}$.

As mães de crianças portadoras de TDAH têm dificuldade em encontrar atendimento especializado para uma melhor avaliação às crianças, ocasionada pela falta de preparo e conhecimento dos profissionais da área da saúde ${ }^{18}$. Desta forma, ter uma ação direcionada ao seu filho, foi motivo de contentamento e aceitação por parte dos cuidadores estudados.

Ah, eu gostei, porque eu gosto quando ele se interessa por uma coisa assim, que seja bom para ele [...] (C2).

Eu fiquei contente, gostei que aí eu sabia que ele ia melhorar, porque quando a pessoa participa de alguma coisa que é para ajudar, acaba melhorando [...] (C5). 
Eu gostei, para ajudar porque... ah, eu acho que para ele também não é bom ter esse tipo de atitude, tem que ter uma coisa que vá controlar ele, para o futuro, para não ter problemas no futuro (C9).

Ah! Nossa agora acho que serão resolvidos meus problemas, não todos, mas, quem sabe amenizar um pouco [...] (C7).

Os pais/cuidadores se sentem sem apoio e ajuda no cuidado a criança/adolescente que enfrenta o transtorno, o que gera um alto nível de estresse, pois recai sobre eles a responsabilidade em relação a educação e o gerenciamento dos conflitos. Assim, torna-se compreensível a expectativa dos pais quanto a um resultado imediato na massagem, visto que sempre estão à procura de algo que lhes dêem uma resposta mais efetiva no tratamento.

Ele está levando mais a sério, chega em casa animado, nos dias de massoterapia, fica lá numa boa, não reclama, deu uma aliviada, só o fato dele ter interesse na massoterapia, já é um passo, já é alguma coisa, e fazer uma coisa que ele está gostando, e levando adiante [...] (C7).

A massagem pode ser uma forma alternativa ao tratamento dos sintomas da criança com TDAH. Estudos relatam que a massagem Tui Na deixa a criança mais atenta na escola, reduz a agitação e agressividade, melhora a qualidade do sono e humor, promove o relaxamento e melhora o relacionamento familiar e social ${ }^{10,26}$, podendo ser uma opção para auxiliar no tratamento, além do uso de medicamentos, trazendo maior resultado em médio e longo prazo.

Pelo relato das crianças/adolescentes aos cuidadores é possível perceber que a massagem teve como resultado imediato a promoção do relaxamento e do sentimento de felicidade, visto que o tratamento causa uma desaceleração do movimento corporal causada pelo ambiente tranquilo e relaxante.

Ele falava assim que ele dormia, e que quando ele acordava, ele estava assim mais calmo, que ria. Então ele ficou bem... ele falou assim 'ah mãe me senti mais calmo, que a professora quando começava a fazer eu dormia o tempo todo'. Ele falou que dormia, que gostava da massagem, que a massagem fazia ele dormir, acalmava (C2).

Na realidade ele... tinha dia que ele dormia mesmo na hora da massagem, ele gostava muito da massagem [...] (C6).

Ele falava que gostava, que era gostoso que relaxa um pouco, não chegava a dormir, porque dizia que se dormisse não aproveitava, mas ele gostou (C5).

Para uma criança agitada, inquieta, com movimentos rápidos, chegar ao relaxamento a ponto de dormir durante a sessão de massagem, entende-se que o resultado obtido foi imediato e satisfatório para os cuidadores.

As crianças/adolescentes que participaram das sessões encararam esta terapia como algo prazeroso, que servia até como incentivo a ir para a escola, visto que as massagens ocorriam após o término das aulas.

Desde o início que ele começou a fazer a massagem, eu já achei bem interessante, esse projeto [...], foi muito bom, porque na realidade além de ajudar ele, acabou estimulando ele a ir para escola também, até no dia que não tinha aula ele ia para massagem, então foi muito bom, em relação ao aspecto da massagem foi fundamental para ele sim (C6).

Ao inserir os filhos em atividades, como a massagem, as quais crianças/adolescentes frequentavam com entusiasmo, os pais sentiram-se mais seguros e dispostos a apoiar a participação dos filhos.

Os pais de crianças com TDAH também sofrem grande nível de estresse, de escutar reclamações de vizinhos, família, escola e amigos sobre o comportamento do seu filho, mesmo os pais mais habilidosos em cuidar de seus filhos podem mostrar-se cansados diante das constantes exigências de uma criança com TDAH. Portanto, esta terapia proposta vai ao encontro à expectativa dos pais em encontrar algo que dê satisfação ao filho e ainda tem como resultado uma resposta positiva em relação ao transtorno ${ }^{26}$. 
A G. que é muito nervosa, ela melhorou mais, acalmou muito a ansiedade, a ansiedade dela deu uma diminuída, ela come compulsivamente pela ansiedade, deu uma diminuída, então isso a gente viu como os pontos positivos assim, que faz dois anos que ela faz a terapia com a psicóloga, e a massagem ajudou, porque só terapia de dois anos a gente não estava tendo resultado em trabalhar esse emocional dela, da ansiedade. E a massagem ajudou porque nós vimos esse resultado após a massagem (C1).

As crianças/adolescentes diagnosticadas com TDAH sofrem estresse, visto que precisam se esforçar nos estudos e geralmente recebem uma atenção negativa, tanto na escola, quanto em casa e na sociedade. Portanto, terapias complementares não tratam a causa, porém, podem ajudar a criança a lidar com esse estresse, acalmando ${ }^{26}$.

Em duas sessões ele já mudou. Já vi resultado , já vi resultado assim dele dormir [...] (C2).

Ele melhorou bastante [...] melhorou. Na escola também os professores falaram que ele melhorou (C4).

Ele ficou melhor, principalmente no estudo, para fazer alguma coisa, até que ele é meio paradinho, para assistir tv, ele gosta de ficar no computador, então ele está calmo, ele não está aquela criança assim agitada, sabe (C5).

Ânimo! Mais ânimo, quando chega o dia, era na segunda parece. 'Óh, hoje tem massoterapia' ele dizia: 'eu sei!' Porque quando é uma coisa que ele não quer fazer, ele nem quer lembrar, então os dias de massoterapia, ele estava mais animado [...] Ele deu um pouco de melhora, porque ele pelo menos agora participava um pouco mais, se vê pelo que está escrito no caderno, antes ele quase não copiava, esse ano ele já deu uma melhoradinha, copia, participa mais, teve época que o caderno, ele só começava o ano, então esse ano agora o caderno tem mais atividade escrita (C7).

Foi possível perceber, por meio dos depoimentos, uma aceitação entre os cuidadores em relação aos efeitos da massagem. Houve uma avaliação positiva, onde as crianças/adolescentes apresentaram-se mais calmos, com melhor coordenação motora, mais atentos e dispostos ao contato familiar e as atividades escolares. $\mathrm{E}$ quanto ao uso de medicamentos para o tratamento das crianças/adolescentes com TDAH em estudo, percebeu-se que as dosagens foram reduzidas pelos cuidadores.

Foi bom. A tranquilidade deles, assim está mantendo [...] O M. mesmo, ele está sem o remédio, ele, eu senti, melhoras no estudo dele, ele procurou correr atrás do prejuízo que ele estava na escola, ele se concentrou mais [...] gente viu assim, a melhora [...] a melhora do amadurecimento da cabecinha dele, e ele está sem medicamento, até vou ter que passar isso pra neuro[...] então está sendo muito legal. Então, senti que a massagem fez a diferença (C1).

E ele estava usando Vyvanse®, e ele tinha assim dificuldade, ele perdia a coordenação motora, com a massagem ele ficou mais tranquilo, a gente percebeu que a coordenação dele melhorou, mesmo a gente fazendo alguns auxílios de exercícios e ele está sem medicamento há três meses (C1).

Tem dias assim que mesmo não dando medicamento ele está bem mais calmo, ele está mais atencioso, mais disciplinado (C3).

Os depoimentos mostram que os cuidadores reduziram as dosagens de medicamentos para as crianças/adolescentes após o início das sessões de massagem Tui Na. Estudo descreve crianças tratadas com massoterapia ao qual algumas delas deixaram de tomar ou reduziram o uso de medicação ${ }^{26}$.

Pesquisa realizada na Escola de Medicina da Universidade de Miami, mostraram que crianças/adolescentes diagnosticados com TDAH que receberam massagem, quando comparados a outros que não receberam, consideraram-se mais felizes e mais focados nas tarefas. Para tanto, utilizar técnicas simples e naturais podem manter a saúde integral e aliviar o estresse dos escolares ${ }^{27}$. 


\section{Considerações Finais}

A partir deste estudo foi possível observar que as crianças/adolescentes sofrem discriminação perante seus amigos, tanto no ambiente escolar, quanto social, sendo possível ver nos olhos e ouvir nas falas dos cuidadores o sofrimento, que em algumas vezes, foi expresso por lágrimas durante as entrevistas.

A preocupação dos cuidadores foi direcionada à escola e à vivência que a criança tem neste ambiente, pois percebese que na escola existe a falta de conhecimento, de preparo e tolerância por parte dos profissionais da educação em trabalhar com crianças/adolescentes com TDAH.

Após a realização das sessões de massagens as crianças/adolescentes demonstraram maior receptividade com as atividades escolares, bem como, melhoraram o nivel de concentração, de atenção, de alegria e bem-estar.

Desta forma, tem-se que o resultado obtido com a massagem Tui $\mathrm{Na}$, em curto prazo, foi de muita valia aos cuidadores e as crianças/adolescentes que têm o diagnóstico de TDAH, visto que todas apresentaram um relato positivo sobre a mudança de comportamento de seus filhos. Isso foi expresso também ao final das entrevistas, onde as depoentes relatavam a vontade de que fosse dado continuidade ao projeto proposto, pois acreditavam no resultado positivo da intervenção da massagem Tui $\mathrm{Na}$.

Os resultados encontrados têm a intenção de motivar novos estudos e que atendam o maior número de crianças, faixas etárias diferenciadas, e também entrevistas para identificar o conhecimento e as dificuldades dos profissionais da educação em trabalhar com crianças/adolescentes diagnosticados com TDAH.

\section{Referências Bibliográficas}

1. Paiano M, Andrade BB, Cazzoni E, Araújo JJ, Waidman MAP, Marcon SS. Distúrbios de conduta em crianças do ensino fundamental e sua relação com a estrutura familiar. Rev Bras Cres Desen Hum. 2007;17(2):111-21.

2. Amaral AB, Santos CO, Rosa CK, David MC, Przybyszeweski T. A formação do professor para trabalhar com crianças que apresentam diagnóstico de TDAH no ensino fundamental I na rede municipal de ensino de Curitiba. Revista Eletrônica do Curso de Pedagogia das Faculdades-OPET. 2013;Dez:1-11.

3. Polanczyk GV, Casena EB, Miguel EC, Reed UC. Transtorno de déficit de Atenção/hiperatividade: Uma perspectiva científica. Clinics. 2012; 67(10):1125-26.

4. Sena SS, Souza LK. Percepção dos pais sobre amizade em crianças típicas e com TDAH. Psic. Clin. 2013;25(1):53-72. 5. Silva ABB. Mentes Inquietas: entendendo melhor o mundo das pessoas distraídas, impulsivas e hiperativas. São Paulo (SP): Editora Gente; 2003.

6. Desidério RCS, Miyazaki MCOS. Transtorno de Déficit de Atenção/Hiperatividade (TDAH): orientações para a família. Rev Associação Brasileira de Psicologia Escolar e Educacional (ABRAPEE). 2007;1(1):165-78.

7. Fhemig, Fundação Hospitalar Estado Minas Gerais. TDAH, Diagnóstico e Tratamento do Transtorno do Déficit de Atenção e Hiperatividade em Crianças e Adolescentes. Protocolo Clínico 026. 2011. [citado em: 18 abr 2013] Disponível em: www.fhemig.mg.gov.br/pt/protocolos-clinicos

8. Rohde LA, Halpern R. Transtorno de déficit de atenção/hiperatividade: atualização. Jornal de Pediatria. 2004; 80(2):61-70. 9. Algeri S, Zottis GAH. Atribuições do Enfermeiro no Cuidado à criança com Transtorno de Déficit de Atenção/ Hiperatividade. In. Leite MMJ. Proenf. Programas de Atualização em Enfermagem. Saúde da Criança e do Adolescente. Porto Alegre: Artmed/Panamericana. 2006. Ciclo 3. Módulo 1. 2006.

10. Siraichi JTG, Araujo JP, Fernandes JG, Pinto RR, Pizzolo ARD, Santos ESM, de Oliveira ARG, Martinelli F. Percepção da massoterapeuta e da mãe sobre a intervenção da massagem Tui Na como terapia complementar na melhora da sintomatologia do transtorno de déficit de atenção com hiperatividade: um estudo de caso. Cad. Naturol. Terap. Complem. 2013;2(2):83-91.

11. Araujo M, Silva SAS. Comportamentos indicativos do transtorno de déficit de atenção e hiperatividade em crianças: alerta para pais e professores. Revista Digital - Buenos Aires. 2003; 9(62). [citado em: 10 mar 2013]. Disponível em: http:// www.efdeportes.com/efd62/atencao.htm/

12. Bardin L. Análise de conteúdo. Lisboa (PT): Edições 70; 2011.

13. Brasil. Ministério da Saúde. Conselho Nacional de Saúde, Comitê de Ética em Pesquisa em Seres Humanos. Resolução 466/12, de 12 de dezembro de 2012: diretrizes e normas regulamentadoras de pesquisas envolvendo seres humanos. Brasília, DF, 2012. 
14. Jou GI, Amaral B, Pavan CR, Schaefer LS, Zimmer M. Transtorno de déficit de atenção e hiperatividade: um olhar no ensino fundamental. Psic. Reflexão e Crítica. 2010;23(1):29-36.

15. Carmo RA, Gonçalves AG. Influências da família e da escola para o desenvolvimento da criança com transtorno de déficit de atenção e hiperatividade - TDAH. Rev Cien Eletônica de Pedagogia. 2007;09.

16. Figueira MC, Silva JA. A importância de se identificar cedo se a criança é portadora de transtorno de déficit de atenção com hiperatividade TDAH. Caderno Multidisciplinar de Pós-Graduação da UCP. 2010;1(1):65-78.

17. SchilkALT. Aeducação além dos muros da escola. $1^{\circ}$ Encontro Nacional Sobre Atendimento Hospitalar. Psicopedagogia Hospitalar- Reflexão do Evento Psicopedagógico. Universidade do Estado de São Paulo. Psicopedagogia Hospitalar: Intermediando a Humanização na Saúde, Edição I, 2008.

18. Balbi C, Ribeiro CA, Borba RIH, Pinto JP. Compreendendo a vivência de ser mãe de uma criança com transtorno de déficit de atenção e hiperatividade. Anais do III Congresso Brasileiro de Enfermagem Pediátrica e Neonatal e XVI Encontro Catarinense de Enfermagem Pediátrica Florianópolis, 06 a 08 de outubro de 2009: Florianópolis, SC: SOBEP, 2009.

19. Leão LGR. O fenômeno Bullyng no efeito escolar. Revista FACEVV. 2010;04: 119-35.

20. Falcão MLC. A inclusão escolar de alunos com tdah: um estudo de caso no município de Ipatininga-MG. Universidade de Brasília - UNB, Programa de Pós-Graduação em Processos de Desenvolvimento Humano e Saúde PGPDS, 2011.

21. Trovo MM, Silva MJP, Leão ER. Terapias alternativas/complementares no ensino público e privado: análise do conhecimento dos acadêmicos de enfermagem. Rev Latino-am Enfermagem. 2003;11(4):483-89.

22. Sharpe PA, Williams HG, Granner ML, Hussey JR. A randomised study of the effects od massage therapy compared to guided relaxation on well-being and stress perception among older adults. Complementary Therapies in Medicine. 2007;15:157-63.

23. Cassar P. Manual de Massagem Terapêutica: um guia completo de massoterapia para o estudante e terapeuta. São Paulo: Manole, 2001.

24. Montagu A. Tocar: $O$ significado humano da pele. São Paulo: Summus, 1988.

25. Rossi E. Acupuncture and Tuina for Hyperactive Children. Journal of Chinese Medicine. 2010;94:9-17.

26. Sinclair M. Massoterapia pediátrica. $2^{\mathrm{a}}$ Ed. Barueri, SP. Manole. 2008.

27. Andrews S. Tocar é educar. Revista Epoca. 2006. Edição n.447. [citado em 28 abril 2015]. Disponível em: http:// revistaepoca.globo.com/Revista/Epoca/0,,EDG75920-6048-447,00.html

\section{Juliane Pagliari Araujo}

Endereço para correspondência - Rua: André Gallo, $n^{\circ} 110$ apto $102 \mathrm{~A}$, Bairro: Vale dos Tucanos, CEP: 86046-540, Cidade: Londrina, PR, Brasil.

E-mail: juliane.pagliari@ifpr.edu.br

Lattes: http://lattes.cnpq.br/8437696861651312

Luciana Cláudia Rizzo Lima - lucianaclaudiar@hotmail.com

Juliana Gomes Fernandes - juliana.gomes@ifpr.edu.br

Simone Roecker - simone.roecker@ifpr.edu.br

Jackeline Tiemy Guinosa Siraichi - jackeline.guinosa@ifpr.edu.br

\section{Enviado em 14 de setembro de 2014. Aceito em 25 de maio de 2015.}

